\title{
Space matters: geographic variability of electoral turnout determinants in the 2012 London mayoral election
}

\author{
Ewan Mansley ${ }^{1}$ and Urška Demšar ${ }^{1}$ \\ ${ }^{1}$ School of Geography \& Geosciences, University of St Andrews, Scotland, UK
}

\begin{abstract}
:
Electoral participation is an important measure of the health of a liberal democracy. The determinants of voter turnout have been examined across a range of elections, but geographical approaches are relatively rare and are mostly performed at large scale aggregations and for national elections. This paper addresses this gap by exploring geographic variability in relationships between the turnout at a local election and socio-demographic variables at a detailed spatial level. Specifically, we focus on the London mayoral election, an important element of the 21st century local government reform in Britain, which, until now, has seldom been analysed from a geographical perspective. By linking the turnout from the 2012 mayoral election to socio-demographic data from the 2011 Census and doing this at the level of London's 625 wards, for the first time a more detailed picture of the spatially uneven nature of turnout is evidenced than in previous studies which have focused on larger aggregations, typically constituencies. Analysis is approached through spatial analysis using geographically weighted regression (GWR), which enables the investigation of local variations in voting patterns. The results demonstrate that electoral processes do vary over geographic space and that some of the variables that are traditionally assumed to affect the turnout in a specific way, do not do so uniformly over space or even change the direction to the opposite of the traditionally assumed affect in certain locations. Our findings present a starting point for a more detailed investigation as to why this heterogeneity exists and which social processes it relates to.
\end{abstract}

\section{Keywords:}

Electoral geography, turnout, socio-demographic characteristics, geographically weighted regression, spatial variability, spatial analysis. 


\section{Introduction}

Elections are an essential component of any democratic society and are the conventional means by which a population selects individuals to represent them politically (Arrow 1951). An important piece of information from any contested election is the turnout, i.e. the percentage of the eligible electorate who cast a vote. When a large proportion of the electorate participates, democracy is regarded as being healthy, while low turnout is perceived as an indication of the public's lack of interest in the democratic process. Turnout levels decreased dramatically in many countries over the second half of the 20th Century, with the result being that voter turnout is now a significant political and social issue (Franklin 1996, Blais 2000, Blais et al. 2004). In United Kingdom, the participation in general elections fell from a post-war maximum of 83.9 per cent in 1950 to a minimum of 59.4 per cent in 2001, before improving marginally for the two most recent national contests (Rogers and Burn-Murdoch 2012).

Turnout raises questions about accountability, democracy and effectiveness. When turnout is low, concerns are heightened regarding the legitimacy of election results and whether public opinion has been accurately represented (Johnston and Pattie 2006). This is particularly the case since it is not a random sample of the electorate who do not vote, but a self-selected group. While political scientists favour analysing turnout through the use of individual-level (survey) research techniques, electoral geographers concentrate on researching this topic from an area-based perspective, with an interest in accounting for turnout difference between areas. Previous studies have attempted to uncover why there is so much spatial heterogeneity in terms of turnout, but, turnout is a 'puzzle' with its determinants still largely unaccounted for (Geys 2006b, Smeets and Van Ham 2013). In this paper we employ a data-driven methodology to investigate which socio-economic and political characteristics affect the turnout and in particular how the relationships between the turnout and these characteristics vary over geographic space. 
Electoral processes do not exist in a void, they are geographic, that is, they are inherently linked to the locations at which they occur. One of the most important properties of geographic processes is that they vary across space - this property is called spatial heterogeneity or spatial non-stationarity (O'Sullivan and Unwin 2010) and requires specific spatial methods of data analysis in order to disaggregate the different characteristics of the process at different locations. This statement echoes Agnew's (1987) multidimensional place-centred perspective on political behaviour, which postulates that geographical context is crucial in shaping turnout levels. Voting behaviour of individuals may be mediated by where they live; meaning that localised, rather than general, analyses of what shapes participation levels may be more successful in accounting for variations in turnout (Johnston and Pattie 2004). This has been confirmed in Irish (Kavanagh 2006, Kavanagh et al. 2006), Italian (Shin and Agnew 2011) and American studies (Paez 2004, Wing and Walker 2010, Crespin et al. 2011, Foley and Demšar 2013) which all use spatial statistical models to investigate the presence of geographic variability in the processes that lead to election outcomes. In this paper we focus on the turnout for the 2012 London mayoral elections and use Geographically Weighted Regression (GWR, Fotheringham et al. 2002) to develop spatial statistical models that can account for spatially varying relationships. The aim is to explore to what extent can social and political factors be used to explain ward-level variations in turnout and how these relationships vary over geographic space. As far as we are aware, this is the first attempt to use GWR for analysis of electoral results in UK, although UK electoral data were used as a case study in the development of a related local spatial statistical method, the GW Discriminant Analysis (Brunsdon et al. 2007).

We focus on the local elections rather than general elections. It is widely accepted that a higher percentage of the electorate participate in a general election than in local council or European Parliament elections, but Britain's ‘turnout gap' has been noted as being appreciably wider than elsewhere (Orford et al. 2008). This situation persists, despite local democracy being integral to the wider democratic system and playing an important day-to-day role in ensuring that communities function effectively. Similarly, geographical studies of turnout have gravitated towards focusing on national elections, while other, 
subnational, elections have been neglected (Sinnott and Whelan 1992) and we address this gap by focusing on the 2012 London mayoral election. We selected this election as a case study because turnout data are available at a lower level of aggregation than for other types of election, namely parliamentary elections. This increases the number of cases for use in statistical analysis and permits an investigation of local variations in turnout, which is hidden in larger aggregations, typically constituencies or local authorities.

The post of directly elected mayor was established in UK in 1997 as part of a drive to revitalize local politics by appointing individuals with charisma who would provide firm leadership, be accountable for decision-making and, above all, improve political engagement (Hodge et al. 1997, Blair 1998). London provides the most well-known instance of the directly elected mayoral model being applied, with Ken Livingstone as the first being elected in 2000. However, just 34.4 per cent of Londoners exercised their right to vote in this inaugural election (Rallings et al. 2002).

One of the main reasons why there has been a lack of research into subnational election turnout is a paucity of data. Historically, the collection of local electoral data in Britain has been sporadic but this is not the case for the London mayoral elections. A comprehensive set of turnout results are available at the ward level, compiled by the Greater London Authority (GLA), which allows turnout to be analysed at a much lower level of aggregation than is possible for general elections. London's wards had a mean population size of 13,078 in 2011 , compared with 102,400 in London's parliamentary constituencies (Office for National Statistics 2013). At this level of aggregation, the turnout for the 2012 London mayoral election is shown in figure 1 .

Figure 1 somewhere here 
While the overall turnout for the election was 38.4 per cent, there is significant variation between wards across the city, from 19 to 54 per cent. The general trend appears to be that turnout is lower in the east than it is in the west, with the five wards with lowest turnout all located in the Borough of Barking and Dagenham. However, this broad trend disguises many local variations. For example, some wards in westernmost London, specifically those in southern reaches of the Boroughs of Hillingdon and Hounslow, had just as low turnout as wards in the east. Equally, some wards in the east had relatively high turnout, such as the wards of Upminster and Cranham (both Havering), where turnout was over 42 per cent. In some cases dramatic variations in turnout can be seen even between neighbouring wards. In the Borough of Richmond-upon-Thames, participation rates were almost exclusively above 40 per cent, while Roehampton and Putney Heath ward in neighbouring Wandsworth had a turnout of just 25.3 per cent. Similar local variations can be seen in other parts of London and this paper attempts to identify factors that could explain these variations of the turnout and geographically disaggregate the nature of their impact.

The remainder of the paper is structured as follows: in the next section we review the existing literature on turnout at both national and sub-national elections, which we use to build a model for our analysis. Then we provide an explanation of the spatial statistical methods used and a brief review of prior application of these methods in electoral geography. We then describe our analysis and discuss results in terms of the previous evidence for spatial variation in explaining the turnout.

\section{Background}

The two main competing theoretical models often used to explain electoral behaviour are rational choice theory and civic voluntarism. Rational choice models (Downs 1957) proclaim that an individual's decision of whether to participate in an election will derive from a consideration of the benefits of being active in relation to the costs that this action entails. It represents an attempt to explain electoral behaviour by building on work within the political economy by Arrow (1951), and establishes a direct analogy 
between consumers and voters and between businesses and political parties. As consumers, voters are assumed to be rational actors who seek to maximise their personal benefits, while minimising their personal costs. According to rational choice theory, the voter is concerned with making a decision based on 'utility', therefore taking into account which party's proposed policies will make a discernible improvement to their circumstances. However, if the costs of voting are too great (e.g. the effort required to gather information on candidates' policies and the time taken to vote) or the benefits too few, then an individual is less likely to participate.

Pivotality, which is the probability that a citizen casting a single vote will enable a favoured candidate to win or prevent a less-favoured candidate from being victorious (Clarke et al. 2004), is also relevant to the rational choice model. This is a calculation of whether an individual voting will make a difference to the election result and leads to the prediction that, “...turnout will be higher the closer the election” (Grofman 1993). Accordingly, academics have set about testing the hypothesis that voter turnout increases as an election becomes (or is at least perceived by the electorate to become) closer. A number of measurements of 'closeness' have been suggested, including the absolute difference in votes for and against in a twohorse race (Cox 1988), the percentage difference in votes cast between the winning and second placed candidate (Matsusaka 1993) and the marginality in the preceding election (Denver and Hands 1974). Of these variables, the third has repeatedly proved to be a statistically significant predictor of turnout in British elections (Mughan 1986, Lutz 1991, Denver and Halfacree 1992, Whiteley et al. 2001, McAllister 2001).

Rational choice theory can be critiqued for a number of reasons. A truly rational voter will realise that the likelihood of their vote proving crucial in determining the election result is extremely small and therefore assess that the election outcome will not change whether or not they participate. However, if every voter is assumed to be rational, then each individual will conclude that every other member of the electorate will vote, and will therefore abstain. Yet, while turnout is lower than it has been historically, it is still far 
from being negligible. This constitutes "the paradox of (not) voting" (Geys, 2006a), which provides the necessary leverage for critics of rational choice theory to declare that it, "does not seem to work" (Blais, 2000). It seems unlikely that voters are truly rational, as each individual would need to possess a considerable amount of accurate information about their own interests and proposed policies. Nevertheless, the 'previous marginality' variable identified in this theory has been shown to be significant within the British electoral context.

The second widely supported theory of electoral participation is the civic voluntarism. This model has its roots in the USA (Verba and Nie, 1972) but it has also been utilised to explain participation in other countries, including Britain (Parry et al., 1992; Pattie et al., 2003). At the centre of this approach lies a socio-economic understanding of turnout, as the key concept is that social contexts aid individuals to obtain resources and skills, both economic and cognitive, which enable people to engage with politics (Clarke et al., 2004). The argument is that the resource-rich are more likely to turn out than the resourcepoor, and that those excluded from participating in elections might also be those members of society who are at greatest risk of being socially excluded. Study after study confirms that voters are usually more affluent, of a higher social class and older than non-voters (Lipset 1960, Crewe 1981, Leighley and Nagler 1992, Pattie and Johnston 1998).

Educational attainment is also perceived to be a vote-relevant resource under the civic voluntarism approach, as education increases access to political information and enhances an individual's ability to process this information in a manner that is conducive to making a political decision (Wolfinger and Rosenstone 1980).

In UK, the individual level participation in national elections has been examined since the 1970s. Using British Election Study data for the period 1966-1974 Crewe et al. (1977) examined the social background and political attitudes of non-voters in four parliamentary elections, finding only three variables being 
statistically significant: residential mobility, age and housing tenure. Non-participation was most prevalent among newcomers to an area, who were yet to develop local ties and may have incurred higher voting 'costs' if they were registered in a different ward. In relation to age, "the younger an elector, the less likely he or she will vote regularly" (Crewe et al, 1977) but it is probable that this relationship was influenced by younger people also likely being residentially mobile. Finally, the association between voting and housing tenure distinguished between privately and socially rented housing. Council tenants generally live within well-defined communities and are more exposed to the social pressures to vote than private renters who are often scattered across localities. Swaddle and Heath (1989) confirms findings of Crewe et al. (1977) regarding the significance of length of residence and age. However, they find that class and income level are also important, with those in the highest income and status groupings participating most in elections. Eagles and Erfle (1989) found strong correlations between turnout and owner occupancy. Areas with more homeowners were prone to having enhanced participation rates, because ownership confers a sense of rootedness to a particular place, compared to the instability of renting. A similarly strong association has been found by Johnston and Pattie (2006).

At the subnational level, Miller's (1988) report for the Widdicombe Committee is the most thorough and sophisticated analysis of local turnout patters in the United Kingdom. However, as his research was conducted on behalf of the government, we must be cognisant of the report's political value and the inherent danger of bias. Miller's survey, involving 1000 respondents, aimed to provide a more in-depth understanding of local government than had previously been achieved. Miller's findings on the characteristics of local voters and abstainers are, to a reasonable extent, consistent with those found using general election data. Older members of the electorate were more likely to vote than those in younger age groups, while long-term residents voted more frequently than individuals who had recently moved. Interestingly, Miller observed that the association between housing tenure and turnout was contrary to that observed when analysing parliamentary elections. 
Considering London, Rowley (1971) conducted an analysis into turnout variations in the 1964 and 1967 Greater London Council (GLC) elections from a geographical perspective. He suggested a concentric model of electoral participation, with a central area of high turnout in traditionally Conservative boroughs (Kensington and Chelsea and Westminster), surrounded by an inner ring of Labour-supporting areas with lower turnout and a peripheral zone of suburban Conservative boroughs with considerably higher turnout. Figure 1 however shows that such a simplistic understanding of turnout variations in London is not appropriate. Rowley's results, "indicate that lower turnout is apparently associated with the safety of the seat", with marginal boroughs having higher turnout due to the potential importance of each vote. A divergent conclusion was reached by Newton (1972), who contended that local voting and participation were more likely to be influenced by happenings in national politics than by the spatial marginality of particular electoral districts.

A successor of the GLC, the GLA, has received very little research attention, despite assertions that the introduction of a directly elected mayor would have a positive effect on turnout levels. The only study that has sought to investigate participation in a London mayoral election was undertaken by Curtice et al. (2008) using survey data linked to the first election in 2000. The primary focus of their research was to examine how Londoners' attitudes towards the new institutions affected turnout but an additional finding was that demographic factors commonly associated with non-voting in national elections, such as being young and a member of an ethnic minority, were also associated with abstention in the inaugural mayoral election.

Most of the above-reviewed studies researched electoral participation by employing a survey-based approach. The advantages of this are that a wide range of variables (including social-psychological factors) can be drawn upon and that direct inferences can be made about the behaviour of individuals. However, research of this type is limited due to small samples. The alternative is employing an aggregate 
data approach, which uses the actual election results and area characteristics as variables and also considers geographical variations.

In Britain, aggregate data have been used at ward-level to account for spatial variations in subnational election turnout (Rallings and Thrasher 1990, 1994, 1997, 2006, Geys 2006b). The most robust finding is a clear relationship between levels of turnout and the affluence of an area, while they also report that socio-economic variables consistently prove to be statistically more important than political variables in accounting for turnout differences (Rallings and Thrasher 1997).

Only a handful aggregate data analyses for British elections have been published from a geographical perspective. Taylor (1973) considered whether residents who live nearby polling stations are more likely to vote than those who have the added 'cost' of travel. Morlan (1984) has investigated the importance of electorate size, finding that electoral districts with smaller populations are associated with greater levels of electoral participation. Orford et al. $(2008,2009,2011)$ use a set of spatial analysis techniques including spatial autocorrelation measures and multilevel modelling to investigate various aspects of turnout in the London borough of Brent. Arzheimer and Evans (2012) investigated the effect of geographical distance between the electorate and the origin of the candidate on voting behaviour. Detailed spatial studies are however still relatively rare. In this paper we present an attempt to counter this trend and investigate spatial turnout patterns using local statistical methods on aggregate data.

\section{Data}

In this study we used three data sources: a turnout data set of the 2012 London mayoral election, socioeconomic data from the 2011 Census for England and Wales and ward boundary data. 
Turnout data were produced by the London Elects (http://www.londonelects.org.uk/), the politically impartial element of the GLA responsible for organising the Mayor of London elections. This data set contains information on the candidates, the parties they represent and previous mayoral election results.

We obtained a set of socio-economic variables from the 2011 Census for England and Wales by the Office for National Statistics (http://www.ons.gov.uk/). We selected a set of variables that were highlighted by previous studies as being associated with turnout. We provide the list of selected variables and a rationale for their selection in the next section, where we discuss how we built our model.

All of the variables (turnout and census information) were joined to a spatial data set of 625 London wards, the boundaries and centroids of which we obtained from the Ordnance Survey through the Digimap service (http://digimap.edina.ac.uk).

\section{Methodology}

To explain relationships between the turnout and the explanatory census variables we adopted an established spatial statistical data analysis methodology (Fotheringham et al. 2012), which consists of the following steps: 1) literature-based variable selection, 2) data-driven model optimisation and 3) a calibration and interpretation of the best possible global and local models. In step 1), we selected fourteen potential explanatory variables based on electoral geography literature and in step 2) reduced their number to eight using correlation analysis and model quality optimisation. These eight variables were then used as input into a global and a GWR model in step 3). This section describes the details of our modelling procedure.

\subsection{Step 1: literature-based variable selection}

The initial selection of potential explanatory variables was performed based on literature in section 2 . We selected fourteen variables that were deemed most likely to explain the turnout (table 1). 


\section{Table 1 somewhere here}

The fourteen variables were categorised into seven thematic groups: age, occupation, migration, population, economic deprivation - labour market related, economic deprivation - housing market related and political variables. The following list provides our reasoning behind inclusion of each of these variables per thematic group.

Group 1: Age variables. One of the most robust findings in electoral research is the impact of age on electoral participation indicating a negative relationship between youth and turnout (Byrne 1983, Blais 2000, Bhatti et al. 2012). Another well-documented age effect is the positive relationship between turnout and percentage of middle-aged inhabitants (Milbrath and Goel 1977) as well as elderly inhabitants (Goerres 2006). We include four age variables into our model, which span the entire age range of population eligible to vote: ages 18-29, 30-44, 45-64 and 65+. Based on the literature we expect a negative relationship between turnout and the first category and a positive relationship with the rest of the categories.

Group 2: Occupation: there are two variables in this group: students and professional\&managerial occupations.

Percentage of students: Civic voluntarism suggests that education is an important resource which facilitates voting. When age is controlled for, students have higher turnout than non-students, as those within educational institutions may be motivated to vote through social pressure and greater access to political information (Hillygus 2005, Bhatti et al. 2012). We therefore expect a positive relationship with turnout. 
Percentage of population in professional and managerial occupations: there is evidence of a link between occupation and level of turnout (Parry et al. 1992). The variable used in this study is the proportion of residents aged between 16 and 74 who are employed in a professional or managerial role and we hypothesise a positive relationship with the turnout.

Group 3: Migration. This group includes variables describing recent in-migration $(<2$ years $)$ and longerterm change in population (2001-2011).

Percentage of population living in London for less than 2 years: We investigate the extent to which the proportion of ward residents who have been living in London for a relatively short period of time contributes to turnout levels. As a longer-term measure of migration we consider difference in population 2001-2011. Residential mobility has been shown to be an important factor which negatively influences turnout because the 'costs' of voting are higher than for settled residents and may discourage participation, as could the severance of community ties (Verba and Nie 1972, Highton and Wolfinger 2001). For both these two variables we therefore expect a negative relationship with the turnout.

Group 4: Population size. Here we consider population density. It has been suggested that the smaller the size of a ward (in terms of population per area), the higher the level of turnout (Morlan 1984). The rationale behind this is that electorate may feel disconnected from local politics if the population is large. We therefore expect a negative relationship.

Group 5: Economic deprivation - labour market conditions. This group contains one variable: percentage of unemployment, which is the proportion of economically active people in a ward who were unemployed at the time of 2011 census. This variable has been shown to have a negative effect in the British electoral context (Bowyer 2008, Orford 2008, 2011) and we expect a similar outcome. 
Group 6: Economic deprivation - housing market conditions. This group includes three measures: proportions of overcrowded households, households with no central heating and owner-occupied households. The first two measures are proxies for deprived housing market conditions and the third one a proxy for affluent housing market situation.

Percentage of overcrowded households: Overcrowding is defined as the percentage of households with a bedroom occupancy rating of -1 or less (indicating that a dwelling has one less bedroom than required) (Office for National Statistics 2014). The measure of overcrowding used in our model was obtained by subtracting the number of bedrooms required from the number of bedrooms present for each household. As this is a surrogate indicator of income, it is sometimes used to explain the turnout (Barnett 1973, Davies and Newton 1974, Denny and Doyle 2007) - in the older literature it is sometimes referred to as density of occupation or housing density and usually has a negative relationship to turnout.

Percentage of households with no central heating: this variable is commonly included in indices of multiple deprivation as an indicator of underlying social disadvantage (McLennan et al. 2011). As a proxy for this, we anticipate that it will be negatively associated with turnout.

Percentage of owner-occupied housing: Studies have shown that home ownership, which is a major financial investment in an area, makes voting more likely because participating in the electoral process is a way of having a say in the future of that area (Kingston et al. 1984, Sinnott and Whelan 1992). We therefore expect a positive relationship between the owner occupied variable and the turnout.

Group 7: Political context. This group includes the inverse marginality of the 2008 London mayoral election: According to rational choice theory (Denver and Hands 1974), a negative relationship is expected between previous inverse marginality (the percentage victory of the winning candidate over second place) and turnout. That is, if the last contest in a particular ward was tight the electorate should 
remember this and realise that their vote may make more of a difference to who prevails than in nonmarginal wards. A larger proportion of the electorate is therefore expected to cast the vote in wards where 2008 elections were tighter.

\subsection{Step 2: model quality optimisation and variable set reduction}

In this step, the set of fourteen initial variables was reduced, first by removing correlated variables and second by optimising model quality. We first tested the fourteen variables for collinearity by calculating a matrix of pairwise correlation coefficients. Three variables that were highly correlated with the highest number of other variables (table 1) were excluded from further consideration. We defined high correlation as that where the pairwise coefficient exceeded $0.70-$ a value that is typically used to indicate collinearity in multiple regression modelling (Dormann et al. 2013). This left us with eleven variables to be used as input into model optimisation.

In the second part, we optimised the quality of the model by minimising the Akaike Information Criterion (AIC). This criterion or its corrected version (AICc) comes from information theory and is a measure of the quality of a statistical model on a particular set of data (Konishi and Kitagawa, 2008). In local modelling it is used to compare the quality of the global vs. local models (Fotheringham et al. 2002), but it can be used to compare any two models as long as they are calibrated on the same data set. This is done by inspecting the value of this criterion: the lower the value, the better the model quality (Fotheringham et al. 2012).

To find the best model, each of the eleven variables that passed the collinearity test was, in turn, used to calibrate a one-variable GWR model for the turnout (i.e. the dependent variable was percentage turnout in the 2012 London mayoral election and the only independent variable was one of the eleven variables). For each of these eleven one-variable models we calculated the AICc value. The variable with the 
smallest AICc value, indicating the best model quality, was kept. In the next step, the remaining ten variables not selected for the initial model were entered in turn, so that ten different two-variable models were produced. Again the models were calibrated and the variable resulting in the smallest AICc figure was retained as second variable in the final model. This operation was repeated until the AICc did not decrease anymore with the inclusion of an additional variable, indicating that the remaining variables did not improve the model. In our case, this occurred after eight iterations and excluded three variables marked with two asterisks in table 1. Figure 2 illustrates the model optimisation procedure.

\section{Figure 2 somewhere here.}

The final selection of the potential explanatory variables to be used for local modelling therefore includes the following (shown in bold in table 1): age 30-45, age 45-54, percentage of professionals and managers, recent migration, population density, unemployment, overcrowding and inverse marginality.

\subsection{Step 3: Local modelling}

While multiple linear regression is one of the prevailing statistical methods used in quantitative geography, it has limitations when applied to spatial data because it presupposes that the relationships being addressed are the same everywhere. This contradicts one of the major assumptions underpinning geographic thought, which is that spatial phenomena vary across space. GWR addresses this issue by producing a set of local models instead of one global model, with separate parameters estimated for each location in the dataset (Fotheringham et al., 2002). This is achieved by using a specific weighting scheme, under which data points are weighted relative to their distance from the regression point, so that points close to the regression point are more heavily weighted than points further away. Thus, GWR calibration results in not one global estimate of each model parameter, but a surface of local parameter estimates that can be mapped to investigate significant spatial variations in the relationships between the explanatory variables and the turnout. In electoral context, GWR has been used to explore voting processes in a 
number of studies in several countries although not UK (Kavanagh 2006, Kavanagh et al. 2006, Paez 2004, Wing and Walker 2010, Crespin et al. 2011, Shin and Agnew 2011).

Specifically, GWR takes a global regression model, such as the one shown in equation 1, where Y indicates the dependent variable, $X_{j}$ the independent explanatory variables and $\beta_{\mathrm{j}}$ parameter estimates,

$$
Y=\beta_{1} X_{1}+\beta_{2} X_{2}+\ldots+\beta_{n} X_{n}
$$

and challenges the assumption that parameter estimates are constant. Instead, GWR calibrates a local model at each spatial location (i), producing a set of models, where data for each model are taken from a neighbourhood of the location $\mathrm{i}$ and weighted according to their geographic distance to point $i$. The local models are in the following form:

$$
Y=\beta_{1}(i) X_{1}+\beta_{2}(i) X_{2}+\ldots+\beta_{n}(i) X_{n}
$$

where each parameter estimate $\beta_{j}(i)$ is now a function of location $i$ and can be mapped as a surface to investigate if there is any spatial variability present in the relationship between the dependent variable $Y$ and the corresponding independent variable $X_{j}$ (Fotheringham et al., 2002). In our case, we used the selection of eight explanatory variables from the previous section to build both a global and a GWR model for the turnout.

We investigated the presence of spatial variability in the relationship between turnout and each of the eight variables in order to see if a mixed model (i.e. a model where some variables are allowed to vary spatially and others are treated as constant over space) is more suitable for our data than a fully local model. We performed a test of geographical variability, whereas first a full GWR model is built and then for each variable, a mixed model where only this one particular variable is kept constant and all others are treated as spatially varying is calibrated. AICc values are compared for the full GWR model and each mixed model: in each comparison, if there is no decrease in the criterion, this indicates that the respective variable does indeed vary spatially (Fotheringham et al. 2002). In our data this was the case for all eight variables and we therefore selected a full GWR model as our final model. 
Apart from parameter estimate surfaces, GWR also returns spatialised versions of the standard statistical measures for model quality, such as local t-values for each parameter estimate and the local $\mathrm{R}^{2}$ as the measure of explanatory power of the model. These measures are also spatial surfaces rather than constants as in global regression. The local t-value surfaces are used in significance mapping of the parameter estimates: the usual thresholds ( $\mathrm{t}<-1.96$ or $\mathrm{t}>1.96$ for 0.05 significance) are used to visually cut out areas on parameter estimate maps where relationships are not significant. Local $\mathrm{R}^{2}$ surface however demonstrates different levels of model performance in different areas across the extent of the geographic data set (Fotheringham et al. 2002).

A further typical interpretation of the global regression and GWR results is to inspect the spatial distribution of the residuals (Fotheringham et al. 2002). Residuals are defined as the difference between the observed value for Y and the predicted value. In standard statistical modelling, residuals are expected to be independent from each other, which, if put on the map, should result in a geographic distribution that shows no particular grouping (a random distribution). However, if spatial variability is present in the relationships that the global regression models, the corresponding residuals will also exhibit this variability and the pattern on the map will not be random (i.e. areas with similar residual levels will be located close to each other in the geographic space rather than more randomly distributed). As GWR disaggregates this dependency by creating a better fitting local model at each location, GWR residuals are expected to exhibit a spatially more random pattern than global residuals. The level of randomness in global and GWR residuals can be mapped, but it can also be confirmed using some measure of spatial autocorrelation, such as Moran's I (Moran 1950, O'Sullivan and Unwin 2010). Values of this index are between -1 and 1 , where -1 indicates spatial dispersion, 1 indicates spatial clustering and values close to 0 indicate a random spatial pattern. The index is calculated over a neighbourhood of each location and the neighbourhoods can be conceptualised in different ways. We used two conceptualisation types, the first representing the geometrical and the second the topological concept of proximity (Getis 2009). In the first model, the neighbourhood was defined through inverse Euclidean distance squared from the centroid of 
each polygon. We selected this model over the simple inverse distance to correspond to the bi-square kernel in the GWR calculation, which also decreases with the squared distance from each point. In the second model, the neighbourhood consisted of the central polygon and its contiguous polygons using both edges and corners for the definition of the contiguity. In both cases, the spatial weight matrix for Moran's I was row standardised.

\section{Results}

\subsection{Global regression model}

Results of the global regression model are presented in table 2, showing global coefficients and their significance. The adjusted $\mathrm{R}^{2}$ for the global model is 0.64 .

\section{Table 2 somewhere here}

The results of global regression suggest a positive relationship between the turnout and the following variables: age 45-64, percentage of professionals \& managers, overcrowding, marginality and population density. The rest of the relationships are negative in a global model. Three of the identified relationships contradict our hypotheses (section 4.1.): those between turnout and population density, overcrowding and inverse marginality respectively are all positive while we expected a negative result. However, note that the global parameter estimates for these variables are, while positive, also close to zero, and the local parameter estimates for the respective variables vary between maximum positive and minimum negative values. This suggests that the relationship between the turnout and each of these three variables is positive in certain locations and negative in other locations and the global regression averages these descriptions into a value close to zero (albeit positive). 


\subsection{GWR model}

The GWR model was calibrated for the same eight variables as the global regression model. We ran a Gaussian model with an adaptive bisquare kernel, which resulted in the optimal bandwidth of 95 nearest neighbours. This means that a local model for each of the 625 wards was generated using the weighted data from the nearest 95 wards, approximately one sixth of the total number of wards. The local AICc value was 3014.57, which was a considerable decrease from the AICc from the global model (3285.58), indicating improvement in model quality.

\section{Figures 3 and 4 somewhere here.}

Figures 3 and 4 show maps of local parameter estimates, where only the values of each local parameter estimate which are locally statistically significant to the 0.05 level are shown (i.e. all areas where local tvalues for each respective parameter are between -1.96 and 1.96 are shown as white on the maps). Specifically, three variables exhibit a mostly positive relationship with turnout (overcrowding (fig. 3a), professionals and managers (fig. 3b) and population density (fig. 3c)), one exhibits a mostly negative relationship with turnout (unemployment, fig. 3d), The other four are mixed (age 30-44, age 45-54, inverse marginality and recent migration, fig. 4).

Of note are again contradictions with our expectations (section 4.1.). As with global regression, we expected there to be a negative relationship between turnout and overcrowding. However, this relationship, even when modelled locally, is positive almost everywhere where it is statistically significant (fig. 3a).

The other two contradictory results are the specific spatial patterns of positive and negative relationships of ages 30-44 and 45-54 (figures $4 \mathrm{a}$ and $4 \mathrm{~b}$ ). Contradictory to our hypotheses of there being a positive relationship between turnout and both these two population ages, the geographical patterns of these 
relationships are very different. The parameter estimate for ages 30-44 (fig. 4a) is negative in the centre of town and has two positive pockets in the west and south-west. The parameter estimate for ages 45-54 however is positive in the entire west and south-west area and negative in the area around Hammersmith, Fulham, Kensington and Chelsea.

A similar bi-polar (negative and positive) effect is observed between turnout and inverse marginality (fig. 4c) and with recent migration (fig. 4d), although the area where the latter has a significantly positive effect is limited to a few wards in the east.

Another piece of information contained in figures 3 and 4, is where local parameter estimates are not significant, denoted by wards with no colour. This shows where particular variables are not important in accounting for variations in turnout. Considering the eight maps together, a trend can be seen which suggests that the local parameter estimates are generally not significant in the centre of London, except for population density, population aged 30-44 and recent migration. The centre of London also stands out in figure 5, which maps the local $\mathrm{R}^{2}$ values. This map shows that the local model replicates variations in turnout very well in the peripheral boroughs, but performs least well in the central areas, particularly to the east of the City. The average local adjusted $\mathrm{R}^{2}$ for GWR model is 0.79 (averaging values from 0.54 to 0.91, fig. 5), also indicating improvement from the 0.64 adjusted $R^{2}$ of the global model.

Figure 5 somewhere here.

Standard residuals for the global and local model are shown in figure 6. An initial visual inspection of the spatial patterns in these two maps suggests that there is a higher level of geographical clustering of similar residual values in the global map (Fig. 6a) than in the local map (Fig. 6b). The analysis of spatial autocorrelation through Moran's I (table 4) confirms this for both neighbourhood models (geometric and topological). The presence of spatial autocorrelation in the global regression residuals suggests that the 
relationships between the turnout and the explanatory variables are indeed non-stationary and that this geographic variability should be taken into consideration - as we have done by applying GWR.

Figure 6 somewhere here. Table 4 somewhere here.

\section{Conclusions and Discussion}

In this paper we conducted a spatial analysis of the determinants of turnout in the mayoral elections of London in 2012. This is to our knowledge a first attempt of a spatially-disaggregated analysis of electoral results at a relatively detailed spatial level using London's 625 wards. Using a well-known local statistical methodology we built a local model that is in certain areas of London able to explain up to 91 per cent of the variation in the turnout using a set of political and socioeconomic variables (a marked increase from the 64 per cent given by the global model). The model performs less well in the centre of the city, indicating the difference in electoral patterns between the centre and the periphery.

The increase in the explained variance from the global to the local model suggests that there is substantial spatial variation present in the socio-economic and political characteristics that affect the turnout level. The presence of spatial variation was also confirmed through parameter estimates mapping and the analysis of the level of spatial autocorrelation in the distribution of standard global and local residuals. Given that we found that a mixture of socio-economic and political variables that were selected on the basis of both the rational choice theory and the civic voluntarism all affect the turnout in different ways in different locations, this result provides evidence to the idea that turnout is a complex process that cannot be satisfactorily explained with a model that only considers one particular theoretic perspective nor with a model that does not take into consideration location since electoral processes vary across geographic space. In the following we discuss some of the more unexpected results in context of our expectations. 
The first surprising result is which of the variables were found as contributing to the model quality and which were excluded. In particular, some of the socio-economic variables which in other studies have been firmly linked to the turnout, have been excluded in model optimisation, such as the percentage of youth (age 18-29), percentage of elderly (65+) and the education indicator (percentage of students). Further, many previous studies find that socio-economic resources are more important in explaining turnout than political variables. For example, in the context of London, Rallings and Thrasher (1997) studied four editions of London Borough Council elections between 1978 and 1990 and found that, on every occasion, characteristics such as the percentage of households in a borough which were socially rented or overcrowded were statistically more important determinants of turnout than political variables. Our results support this by inclusion of the overcrowding into the final model, but also contradict this in that the political variable describing inverse marginality of the outcome of the previous elections appears to be a locally important determinant of turnout.

An interesting result can be observed in that in a large proportion of wards the relationship with the age group of 30-44 is negative (fig. 4a), in particular in the centre of London, while in some more peripheral wards, the same age group contributes positively to the turnout. This is an unexpected result, as we would expect a negative relationship with a younger age group (which however was eliminated through being collinear). The positive relationship between the age group of 44-64 (the middle aged group) and the turnout, however, is much more prevalent, even though it also shows a centre-periphery difference to some extent (fig. 4b). Also of note is that both the highly negative relationship for 30-44 years' old inhabitants and the highly positive relationship for 44-64 years' old inhabitants correspond to areas where the percentages of the respective age brackets are the highest (fig. 7). That is, the highest negative effect for 30-44 years' old (fig. 4a) is in the wards with the highest percentages of inhabitants of this age (fig. 7a). Similarly, the highest positive effect for 45-64 years' old (fig. $4 \mathrm{~b}$ ) is in the wards with the highest percentages of inhabitants of this age (fig. 7b). 
Additionally, for the latter age category (44-64), a large proportion of wards with a significantly positive effect are wards where the explanatory power of the local model sis the highest (i.e. local R2 of 80 per cent or more, fig. 5). This result is a strong confirmation of the previously observed link between middle age and turnout - however, it is also a strong confirmation that this link is not ubiquitous and that further investigation into this effect should be geographically disaggregated.

\section{Figure 7 somewhere here.}

Further to the effect of inverse marginality, while it has been previously found as a negative predictor, we found a diverging negative-positive effect (fig. 4c). Comparing the effects to the actual inverse marginality values (fig. 8), consider the borough of Bromley in south-east London where the largest effects are observed: in most of the wards in this area, the inverse marginality was high in the previous election, thus probably affecting the choice of not bothering to vote this time. However, inverse marginality was also high in other peripheral boroughs, where there is either no statistically significant effect on the turnout or the relationship is positive, meaning that people did indeed choose to vote in spite of the previous election being easily decided in favour of one particular candidate. Why these differences occurs in particular boroughs is beyond the scope of this study, but it generates an interesting hypothesis to explore in further work.

\section{Figure 8 somewhere here.}

Another discrepancy between the literature-based investigation and our results is the positive relationship between the turnout and the overcrowding, which we found both in local and global models. We speculate that this result might be related to the unique geographical context that London represents within UK, as the city is becoming more and more distinct from the rest of the country. It is well-recognised that the relatively higher house prices and rents in London encourage greater sharing among families and 
individuals who would otherwise occupy separate bedrooms. This leads to 11.3 per cent of London's households being classed as overcrowded, compared to the English average of 4.5 per cent (Office for National Statistics 2014). With space being at such a premium, particularly in central London, this measure may therefore not represent the overall ward-level deprivation as accurately as it does in other regions, thus accounting for a different relationship with turnout in our models as compared with studies of UK elections at a national scale or in different locations than in London.

Conducting a data-driven local spatial analysis proved fruitful in geographically disaggregating electoral patterns and obtaining a more in-depth insight into the specific local determinants of turnout for the 2012 London mayoral election. Our results strongly suggest that the relationships between turnout and the ward-level social characteristics do indeed vary across London. Further research could investigate whether the results found for the London mayoral election hold true for other orders of election, notably parliamentary elections or European elections, using the same variables to allow for comparison. Looking further ahead, it would be interesting to repeat this research for subsequent mayoral elections to ascertain whether, and how, local relationships vary over time.

However, a much more interesting question is to consider the reasons for why some variables are more important for the turnout in some parts of London than in others and why the relationships vary to this level. As Ross and Mirowski (2008) note, it is not possible to fully analyse the contextual effects of place using statistical analysis alone. Spatial statistical methods are useful to identify what is happening where, but they cannot tell us why a particular process operates differently in different locations. For this, further studies would be necessary in order to undertake a detailed local analysis in the areas of London that have been identified as displaying contradictory results to the generally accepted electoral theories. The results from this paper can offer a set of strong hypotheses as a starting point for such an alternative enquiry. 


\section{Acknowledgements}

Our study uses National Statistics data as well as Ordnance Survey data, which both have (C) Crown copyright and database right 2012.

\section{References}

Agnew, J. 1987. Place and politics: The geographical mediation of state and society, Boston: Allen \& Unwin.

Arrow, K. J. 1951. Social Choice and Individual Values, 1st Edition, New York, NY: John Wiley \& Sons. Arzheimer, K. and Evans, J. 2012. Geolocation and voting: Candidate-voter distance effects on party choice in the 2010 UK general election in England. Political Geography, 31: 301-310.

Barnett, M. J. 1973. Aggregate models of British voting behaviour. Political Studies, 21(2): 121-134. Bhatti, Y. and Hansen, K. M. 2012. Leaving the Nest and the Social Act of Voting: Turnout among First-Time Voters, Journal of Elections, Public Opinions and Parties, 22(4): 380-406.

Bhatti, Y., Hansen, K. M. and Wass, H. 2012. The relationship between age and turnout: A roller-coaster ride, Electoral Studies, 31(3): 588-593.

Blair, T. 1998. Leading the Way: A New Vision for Local Government. London: Research Institute for Public Policy.

Blais, A. 2000. To Vote or Not to Vote: the Merits and Limits of Rational Choice Theory, Pittsburgh: University of Pittsburgh Press.

Blais, A., Gidengil, E., Nevitte, N. and Nadeau, R. 2004. Where Does Turnout Decline Come From? European Journal of Political Research, 43(2): 221-236.

Bowyer B, 2008, Local context and extreme right support in England: The British National Party in the 2002 and 2003 local elections. Electoral Studies, 27: 611-620.

Brunsdon, C., Fotheringham, A.S., and Charlton, M., 2007. Geographically weighted discriminant analysis. Geographical Analysis, 39 (4), 376-396.

Byrne, T. 1983. Local Government in Britain: Everyone's Guide to How it All Works, 2nd Edition, Harmondsworth: Penguin.

Clarke, H. D., Sanders, D., Stewart, M. C. and Whiteley, P. 2004. Political Choice in Britain, Oxford: Oxford University Press.

Cox, G. W. 1988. Closeness and turnout: A methodological note, The Journal of Politics, 50(3): 768-775.

Crespin, M., Darmofal, D., and Eaves, C., 2011. The political geography of congressional elections. In: Annual meeting of the Midwest Political Science Association, 31 March - 3 April, Chicago, IL.

Crewe, I. 1981. Electoral participation, in: Butler, D., Penniman, H. R. and Ranney, A. (eds.), Democracy at the polls: A comparative study of competitive national elections, Washington, D.C.: American Enterprise Institute.

Crewe, I., Fox, A. and Alt, J. 1977. Non-voting in British general elections 1966 - October 1974 in: Crouch, C. (ed.) British Political Sociology Yearbook: Vol. III, Political Participation, London: Croom Helm.

Curtice, J. K., Seyd, B. and Thomson, K. 2008. Do mayoral elections work? Evidence from London, Political Studies, 56(3): 653-678.

Davies, P., and Newton, K. 1974. An aggregate data analysis of turnout and party voting in local elections. Sociology, 8(2): 213-231.

Denny, K. J., and Doyle, O. M. 2007. “... Take up thy bed, and vote” Measuring the relationship between voting behaviour and indicators of health. The European Journal of Public Health, 17(4): 400-401.

Denver, D. T. and Halfacree, K. 1992. Inter-Constituency Migration and Party Support in Britain, Political Studies, 40(3): 571-580. 
Denver, D. T. and Hands, H. T. G. 1974. Marginality and Turnout in British General Elections, British Journal of Political Science, 4(1): 17-35.

Dormann, C. F., Elith, J., Bacher, S., Buchmann, C., Carl, G., Carré, G., Garcia Marguéz, J. R., Gruber, B., Lafourcade, B., Leitao, P. J., Münkemüller, T., McClean, C., Osborne, P. E., Reineking, B., Schröder, B., Skidmore, A. K. Zurell, D. and Lautenbach, S. 2013. Collinearity: a review of methods to deal with it and a simulation study evaluating their performance, Ecography, 36(1): 2746.

Downs, A. 1957. An Economic Theory of Democracy, New York, NY: Harper \& Row.

Eagles, M. and Erfle, S. 1989. Community Cohesion and Voter Turnout in English Parliamentary Constituencies, British Journal of Political Science, 19(1): 115-125.

Foley P and Demšar U, 2013, Using geovisual analytics to compare the performance of Geographically Weighted Discriminant Analysis versus its global counterpart, Linear Discriminant Analysis. International Journal of Geographical Information Science, 27(4):633-661.

Fotheringham, A. S., Brunsdon, C. and Charlton, M. 2002. Geographically weighted regression: the analysis of spatially varying relationships, Chichester: Wiley.

Fotheringham, A. S., Kelly, M. H. and Charlton, M. 2012. The demographic impacts of the Irish famine: towards a greater geographical understanding. Transactions of the Institute of British Geographers, 38(2): 221-237.

Franklin, M. N. 1996. Electoral Participation, in: LeDuc, L., Niemi, R. G. and Norirs, R. (eds.) Elections and Voting in Global Perspective II, Thousand Oaks, CA: Sage

Getis, A., 2009, Spatial Weights Matrices. Geographical Analysis, 41: 404-410.

Geys, B. 2006a. 'Rational' Theories of Voter Turnout: A Review, Political Studies Review, 4: 16-35.

Geys, B. 2006b. Explaining voter turnout: A review of aggregate-level research, Electoral Studies, 25: 637-663.

Grofman, B. 1993. Is Turnout the Paradox that Ate Rational Choice Theory? in: Grofman, B. (ed.) Information, Participation, and Choice: An Economic Theory of Democracy in Perspective, Ann Arbor: University of Michigan Press.

Goerres, A. 2007. Why are older people more likely to vote? The impact of ageing on electoral turnout in Europe. The British Journal of Politics \& International Relations, 9(1): 90-121.

Highton, B. and Wolfinger, W. E. 2001. The first seven years of the political life cycle, American Journal of Political Science, 45(1): 202-209.

Hillygus, S. D. 2005. The Missing Link: Exploring the Relationship between Higher Education and Political Engagement, Political Behavior 27(1): 25-47.

Hodge, M., Leach, S. and Stoker, G. 1997. More Than the Flower Show: Elected Mayors and Democracy, London: Fabian Society.

Johnston, R. and Pattie, C. 2004. 'Electoral geography in electoral studies: Putting voters in their place', in: Barnett, C. and Low, M. (eds.) Spaces of Democracy: Geographical perspectives on citizenship, participation and representation, London: Sage.

Johnston, R. and Pattie, C. 2006. Putting Voters in their Place: Geography and Elections in Great Britain, Oxford: Oxford University Press.

Kavanagh, A. 2006. Second order elections and the Republic of Ireland: A spatial perspective on turnout differences between the 2002 General Election and 2004 local elections, 56th Annual Conference of the Political Studies Association (PSA), University of Reading, 3-6 April.

Kavanagh, A., Sinnott, R., Fotheringham, S. and Charlton, M. 2006. A Geographically Weighted Regression Analysis of General Election Turnout in the Republic of Ireland, Political Studies Association of Ireland Conference, University College Cork, 20 October.

Kingston, P. W., Thompson, J. L. P. and Eichar, D. M. 1984. The politics of home ownership, American Politics Quarterly, 12(2): 131-150.

Konishi, S and Kitagawa, G. 2008. Information Criteria and Statistical Modeling. Springer Verlag, Berlin-Heidelberg. 
Leighley, J. and Nagler, J. 1992. Individual and Systemic Influences on Turnout: Who Votes? Journal of Politics, 54(3): 718-738.

Lipset, S. L. 1960. Political Man: the social bases of politics, Garden City, NY: Doubleday \& Company.

Lutz, J. M. 1991. Marginality, Major Third Parties and Turnout in England in the 1970s and 1980s: A ReAnalysis and Extension, Political Studies, 39(4): 721-726.

Matsusaka, J. G. 1993. Election closeness and voter turnout: Evidence from California ballot propositions, Public Choice, 76(4): 313-334.

McAllister, I. 2001. Explaining Turnout in the 2001 British General Election, Representation: The Journal of Representative Democracy, 38(3): 256-267.

McLennan, D., Barnes, H., Noble, M., Davies, J., Garratt, E. and Dibben, C. 2011. The English Indices of Deprivation 2010, Available at:

http://www.communities.gov.uk/docudocum/statistics/pdf/1870718.pdf (Accessed 14 March 2014).

Milbrath, L. W. and Goel, M. L. 1977. Political Participation: How and Why Do People Get Involved in Politics? 2nd Edition, Washington D.C.: University Press of America.

Miller, W. L. 1988. Irrelevant Elections? The Quality of Local Democracy in Britain, Oxford: Clarendon Press.

Moran, P. A. P. 1950. Notes on Continuous Stochastic Phenomena. Biometrika 37(1): 17-23.

Morlan, R. L. 1984. Municipal vs. national election voter turnout: Europe and the United States, Political Science Quarterly, 99(3): 457-470.

Mughan, A. 1986. Party and Participation in British Elections, London: Pinter.

Newton, 1972. Turnout and marginality in local elections, British Journal of Political Science, 2(2): 251255.

Office for National Statistics. 2013. Parliamentary Constituencies Population Estimates, Mid-2011 (Census Based), [Online], Available at: http://www.ons.gov.uk/ons/dcp171778_311961.pdf (Accessed 14 March 2014).

Office for National Statistics. 2014. Overcrowding and Under-occupation in England and Wales, [Online], Available at: http://www.ons.gov.uk/ons/dcp171776_360082.pdf (Accessed 20 April 2014).

Orford, S., Rallings, C., Thrasher, M. and Borisyuk, G. 2008. Investigating differences in electoral turnout: the influence of ward-level context on participation in local and parliamentary elections in Britain, Environment and Planning A, 40(5): 1250-1268.

Orford, S., Rallings, C., Thrasher, M. and Borisyuk, G. 2009. Electoral salience and the costs of voting at national, sub-national and supra-national elections in the UK: a case study of Brent, UK. Transactions of the Institute of British Geographers, 34:195-214.

Orford, S., Rallings, C., Thrasher, M. and Borisyuk, G. 2011. Changes in the probability of voter turnout when resiting polling stations: a case study in Brent, UK. Environment and Planning C, 29:149169.

O'Sullivan, D., and Unwin, D., 2010, Geographic Information Analysis. Chichester: Wiley \& Sons.

Paez, A., 2004. Spatially weighted regression: exploring spatial non-stationarity in multiple contexts. In: $51^{\text {st }}$ annual North American meetings of the Regional Science Association International, 11-13 November, Seattle, WA.

Parry, G., Moyser, G. and Day, N. 1992. Political Participation and Democracy in Britain, Cambridge: Cambridge University Press.

Pattie, C. and Johnston, R. J. 1998. Voter turnout at the British general election of 1992: Rational choice, social standing or political efficacy? European Journal of Political Research, 33(2): 263-283.

Pattie, C., Seyd, P. and Whiteley, P. 2003. Citizenship and Civic Engagement: Attitudes and Behaviour in Britain, Political Studies, 51(3): 443-468.

Rallings, C. and Thrasher, M. 1990. Turnout in English local elections - An aggregate analysis with electoral and contextual data, Electoral Studies, 9(2): 79-90.

Rallings, C. and Thrasher, M. 1994. Explaining Election Turnout: A Secondary Analysis of Local Election Statistics, London: HMSO. 
Rallings, C. and Thrasher, M. 1997. Local Elections in Britain, London: Routledge.

Rallings, C., Thrasher, M. and Cowling, D. 2002. Mayoral Referendums and Elections, Local Government Studies, 28(4): 67-90.

Rallings, C. and Thrasher, M. 2006. Local elections handbook 2006, Plymouth: Local Government Chronicle Elections Centre.

Rogers, S. and Burn-Murdoch, J. 2012. 'UK election historic turnouts since 1918', The Guardian, 16 November [Online]. Available at: http://www.theguardian.com/news/datablog/2012/nov/16/ukelection-turnouts-historic (Accessed 12 March 2014).

Ross, C. and Mirowsky, J. 2008. Neighbourhood Socioeconomic Status and Health: Context or Composition? City \& Community, 7(2): 163-179.

Rowley, G. 1971. The Greater London Council elections of 1964 and 1967: a study in electoral geography, Transactions of the Institute of British Geographers, 53: 117-131.

Shin M and Agnew J, 2011, Spatial Regression for Electoral Studies: The Case of the Italian Lega Nord. In: Warf B and Leib J (eds.), Revitalizing Electoral Geography, Ashgate. Ch. 4, 59-74.

Sinnott, R. and Whelan, B. J. 1992. Turnout in second order elections: the case of EP elections in Dublin 1984 and 1989, Economic and Social Review, 23(2): 147-166.

Smeets, K. and van Ham, C., 2013. The embarrassment of riches? A meta-analysis of individual-level research on voter turnout. Electoral Studies, 32: 344-359.

Swaddle, K. and Heath, A. 1989. Official and reported turnout in the British general election of 1987. British Journal of Political Science, 19: 537-551.

Taylor, A. H. 1973. Journey Time, Perceived Distance and Electoral Turnout - Victoria Ward, Swansea, Area, 5(1): 59-62.

Verba, S. and Nie, N. 1972. Participation in America: Political Democracy and Social Equality, Chicago: The University of Chicago Press.

Whiteley, P., Clarke, H., Sanders, D. and Stewart, M. 2001. Turnout, Parliamentary Affairs, 54(4): 775788.

Wing, S.I. and Walker, J.L., 2010. The geographic dimensions of electoral polarization in the 2004 U.S. Presidential vote. In: A. Paez, J. Le Gallo, R. Buliung, and S. Dall'Erba, eds. Progress in spatial analysis: theory and computation, and thematic applications. Berlin/Heidelberg: Springer Verlag, 253-285.

Wolfinger, R. E. and Rosenstone, S. J. 1980. Who Votes? New Haven, CT: Yale University Press. 


\section{List of Figures}

Figure 1. Turnout at the 2012 London mayoral Election. a) Turnout percentage, b) London boroughs for spatial reference.

Figure 2. Model quality optimisation to select variables for the final model. Initial step is to consider all models with one variable only, out of which the one with the lowest value of GWR AICc is selected (the best of all one-variable GWR models) - in this case unemployment. Then two-variable models are built, adding each of the remaining variables in turn to the selected first variable, and the model with the largest decrease in AICc is kept (in this case containing unemployment and percentage of recent migrants) for the next step, where three-variable models are compared and so on. The procedure stops when there is no more decrease in AICc, i.e. no new variables contribute to further improve model quality. In our case this happens when testing nine-variable models. We therefore select the first eight variables for the final model.

Figure 3. Positive or negative GWR local parameter estimates. Only areas where parameter estimates are significant are shown on the map (areas with non-significant relationships are shown as white). Parameter estimates for a) overcrowding, b) population in professional and managerial professions, c) population density and d) unemployment.

Figure 4. GWR local parameter estimates with positive and negative values. Only areas where parameter estimates are significant are shown on the map (areas with non-significant relationships are shown as white). Parameter estimates for a) age 30 to 44, b) age 45 to 64 , c) inverse marginality and d) recent migration.

Figure 5. Local $\mathrm{R}^{2}$ values for the GWR model. Model performs best in the outer areas of the Greater London and worst in the central areas.

Figure 6. Standardised residuals for a) the global model and b) the GWR model.

Figure 7. Maps showing the two age variables: a) percentage of population aged 30-44 and b) percentage of population aged 45 to 64. Maps are shown with the same colour schemes, to emphasise the complementarity of the two geographical distributions.

Figure 8. Spatial distribution of the inverse marginality. 


\section{Figures}

a)

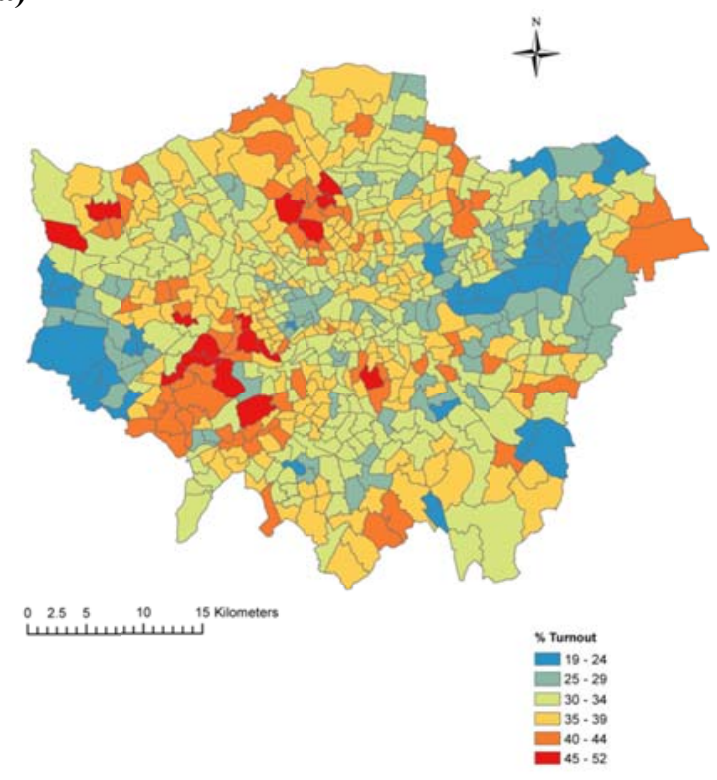

b)

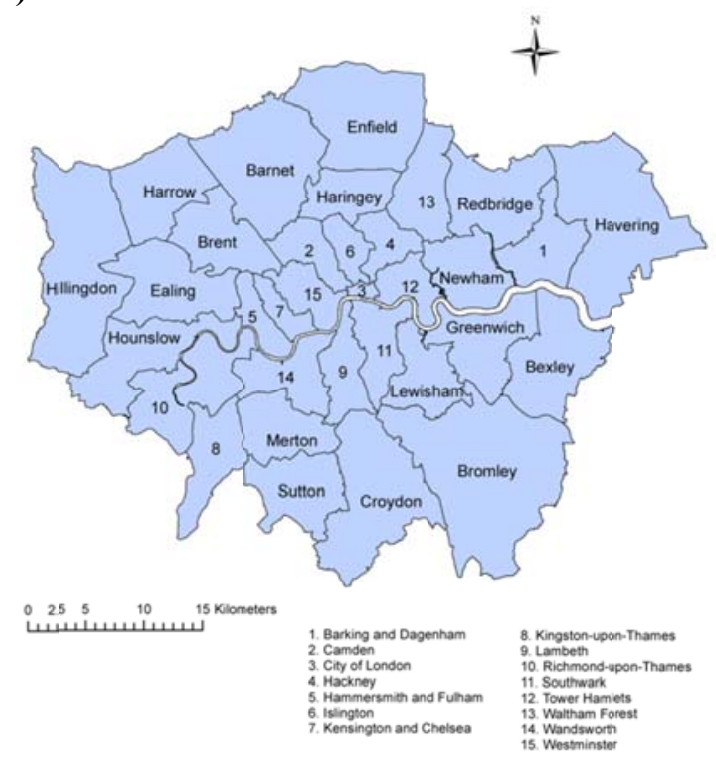

Figure 1. Turnout at the 2012 London mayoral Election. a) Turnout percentage, b) London boroughs for spatial reference. 


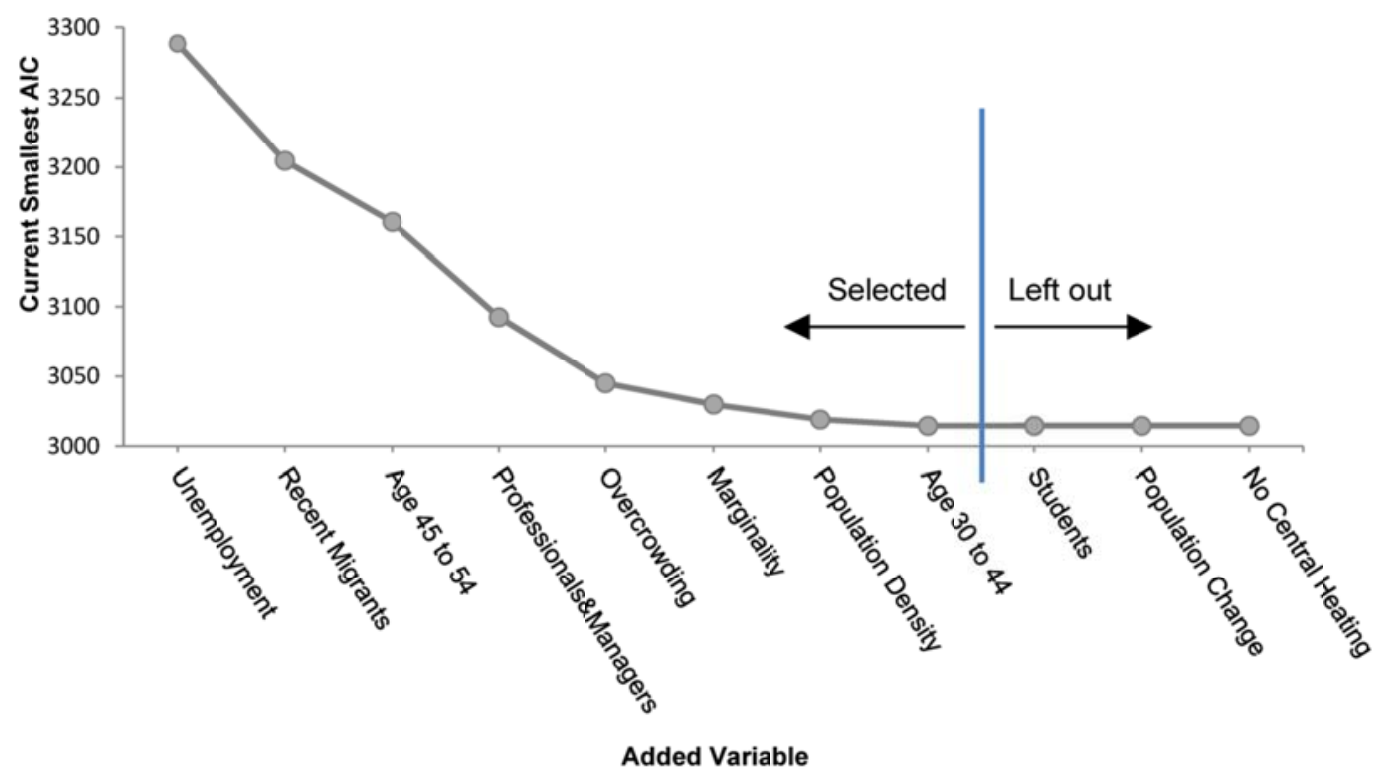

Figure 2. Model quality optimisation to select variables for the final model. Initial step is to consider all models with one variable only, out of which the one with the lowest value of GWR AICc is selected (the best of all one-variable GWR models) - in this case unemployment. Then two-variable models are built, adding each of the remaining variables in turn to the selected first variable, and the model with the largest decrease in AICc is kept (in this case containing unemployment and percentage of recent migrants) for the next step, where three-variable models are compared and so on. The procedure stops when there is no more decrease in AICc, i.e. no new variables contribute to further improve model quality. In our case this happens when testing nine-variable models. We therefore select the first eight variables for the final model. 
a)

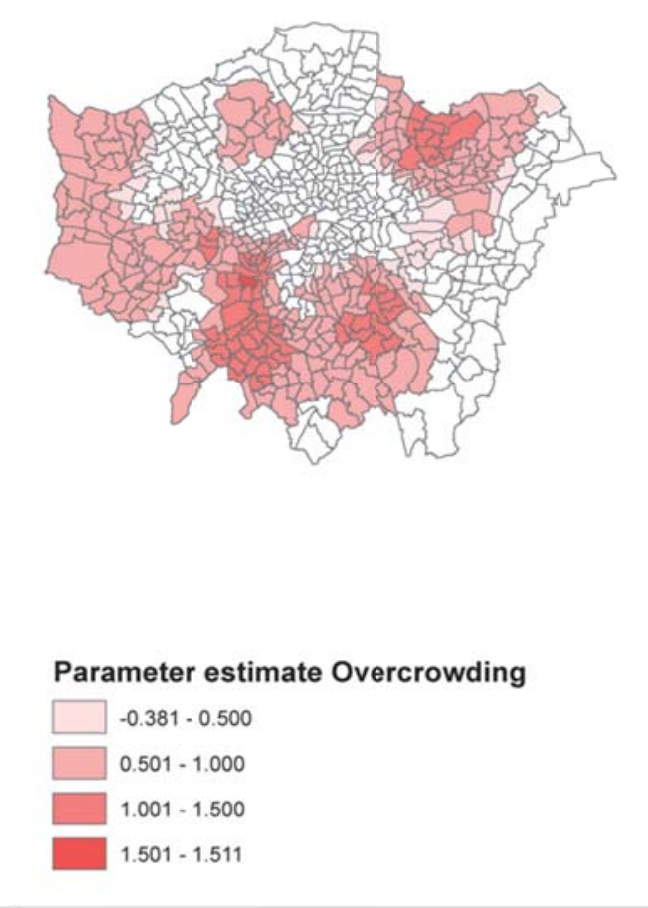

c)

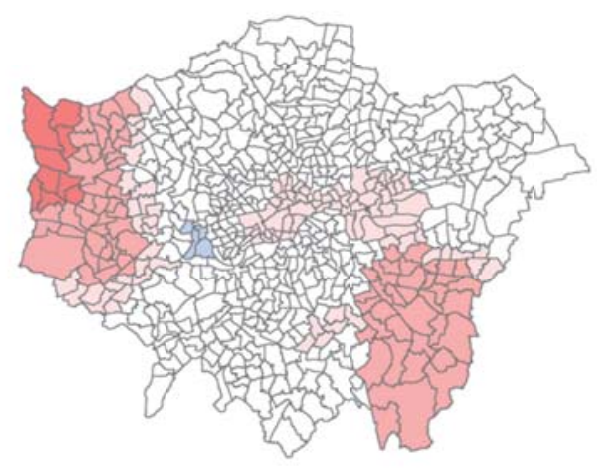

Parameter estimate Population density

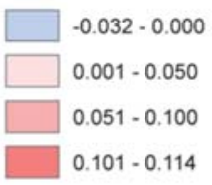

b)

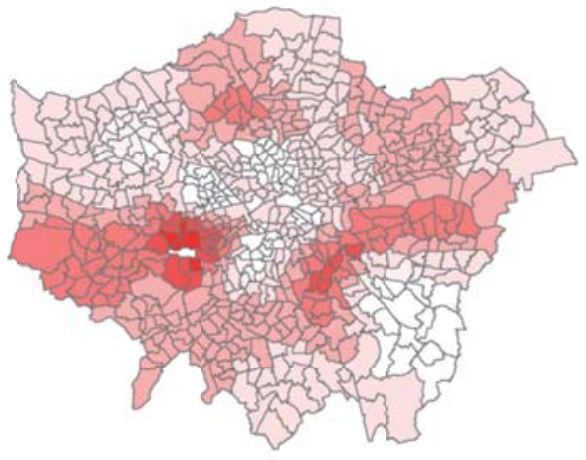

Parameter estimate Prof\&Mgr

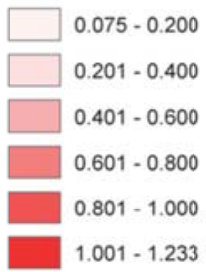

d)

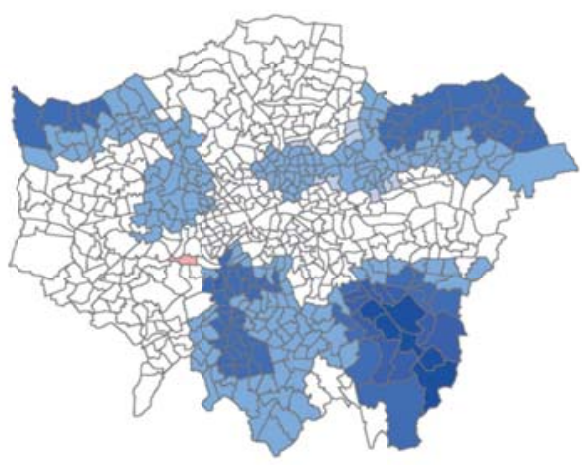

Parameter estimate Unemployment

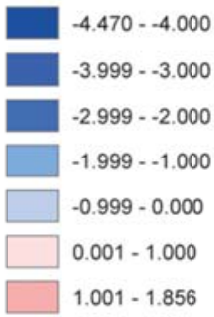

Figure 3. Positive or negative GWR local parameter estimates. Only areas where parameter estimates are significant are shown on the map (areas with non-significant relationships are shown as white). Parameter estimates for a) overcrowding, b) population in professional and managerial professions, c) population density and d) unemployment. 
a)

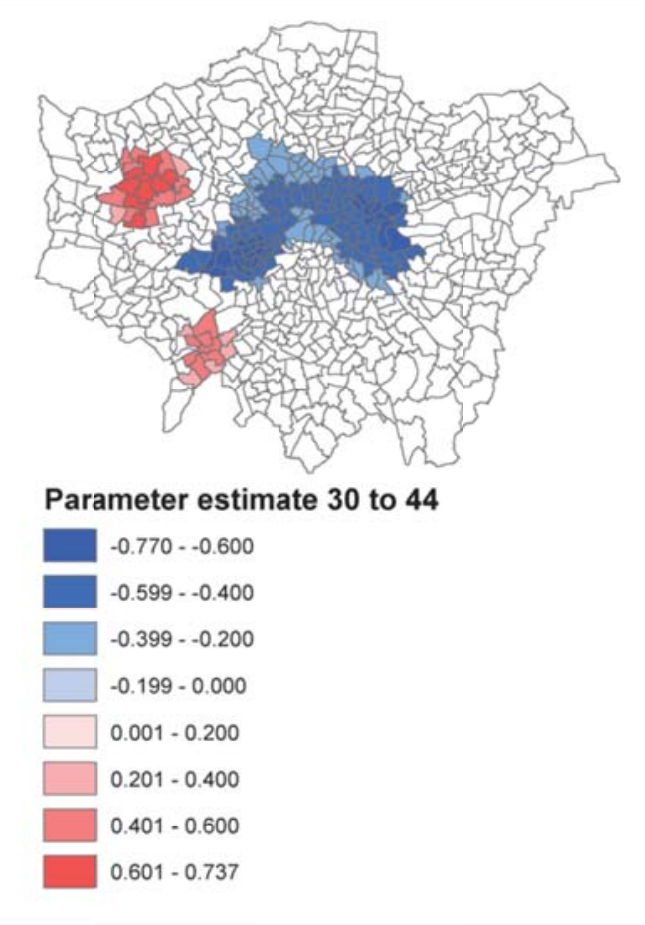

c)

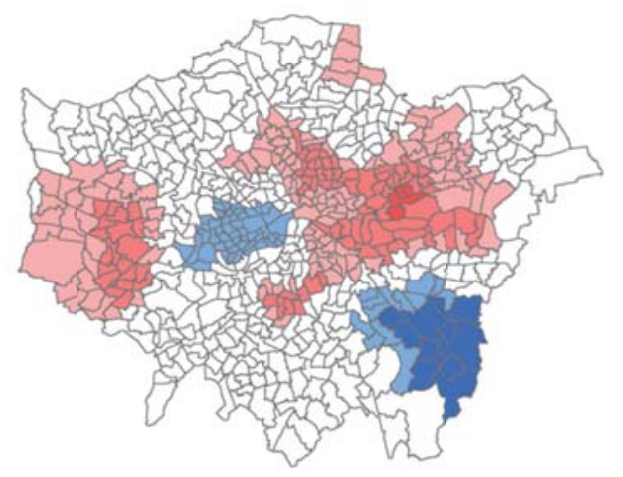

Parameter estimate Inverse marginality

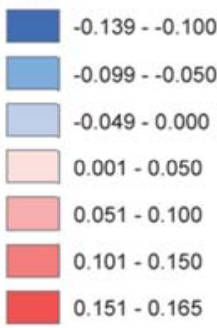

b)

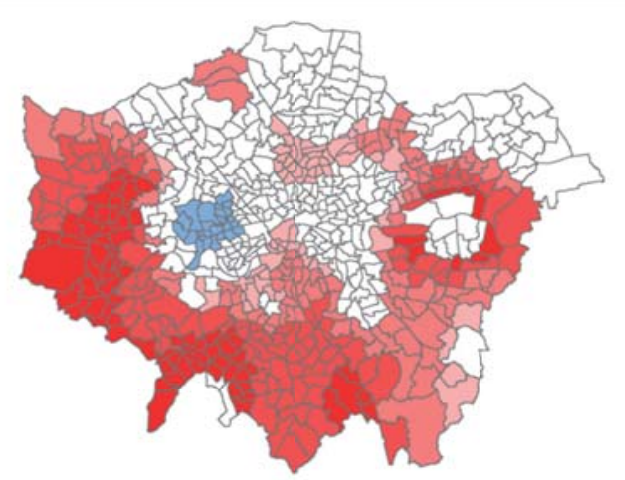

Parameter estimate $\mathbf{4 5}$ to $\mathbf{6 4}$

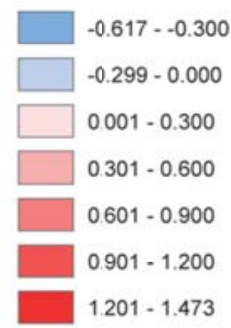

d)

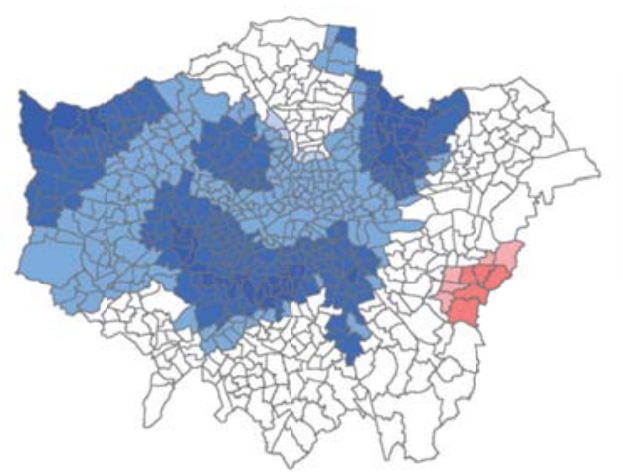

\section{Parameter estimate Recent migration}

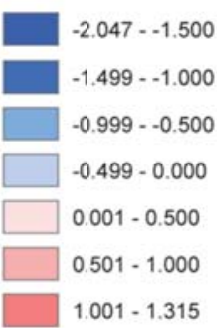

Figure 4. GWR local parameter estimates with positive and negative values. Only areas where parameter estimates are significant are shown on the map (areas with non-significant relationships are shown as white). Parameter estimates for a) age 30 to 44, b) age 45 to 64, c) inverse marginality and d) recent migration. 
Accepted to Electoral Studies (7 Oct 2015)

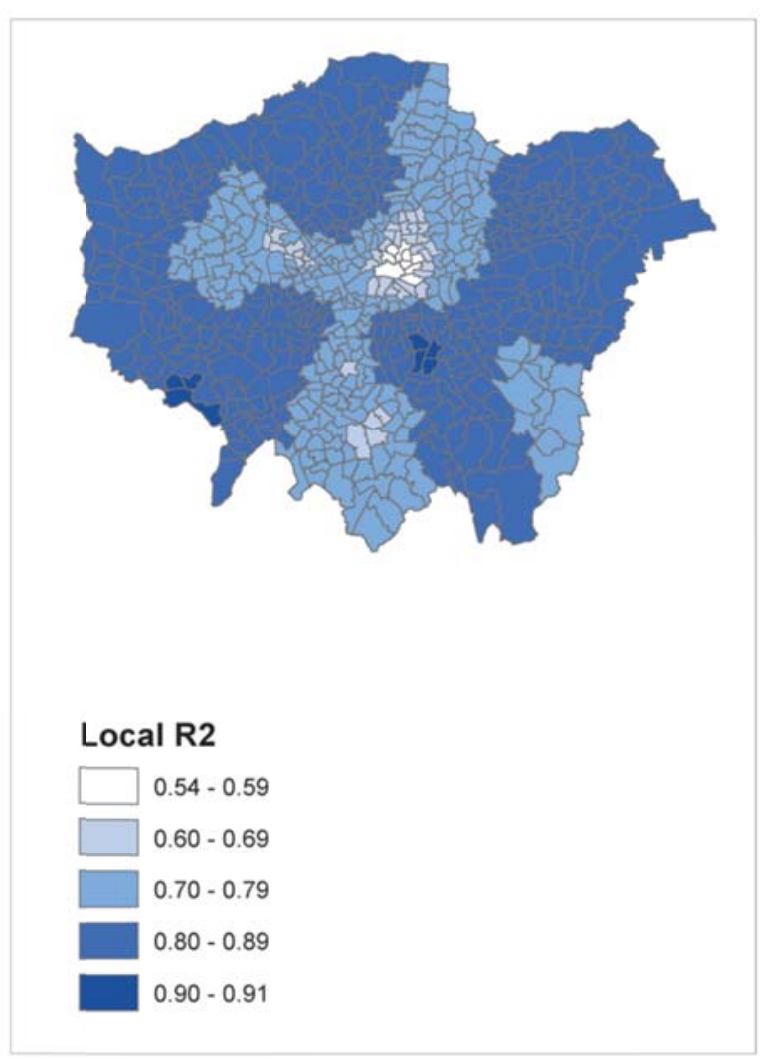

Figure 5. Local $\mathrm{R}^{2}$ values for the GWR model. Model performs best in the outer areas of the Greater London and worst in the central areas. 
a)

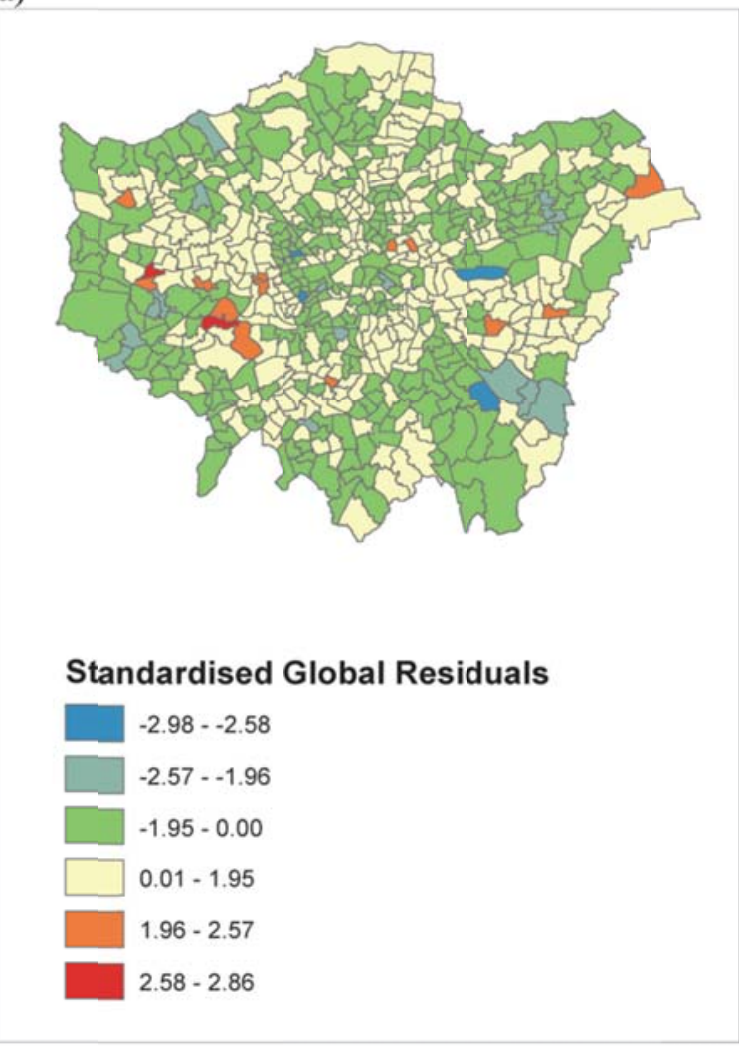

b)

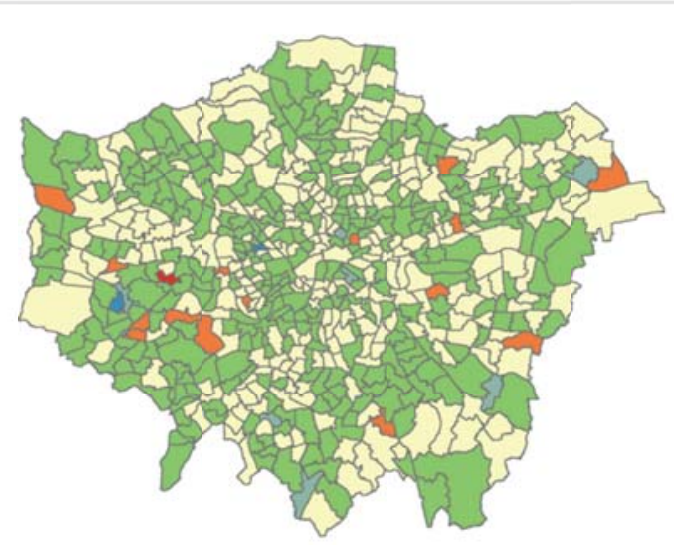

\section{Standardised Local Residuals}
$-2.99--2.58$
$\square-2.57--1.96$
$-1.95-0.00$
$0.01-1.95$
$1.96-2.57$
$2.58-2.62$

Figure 6. Standardised residuals for a) the global model and b) the GWR model. 
a)

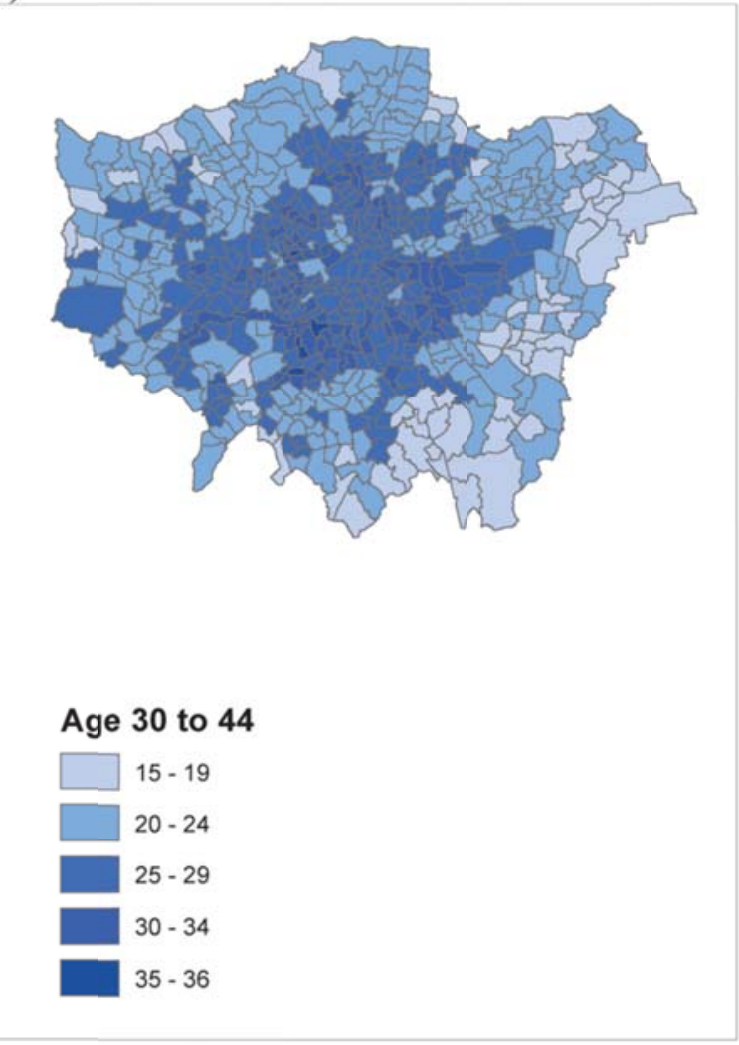

b)

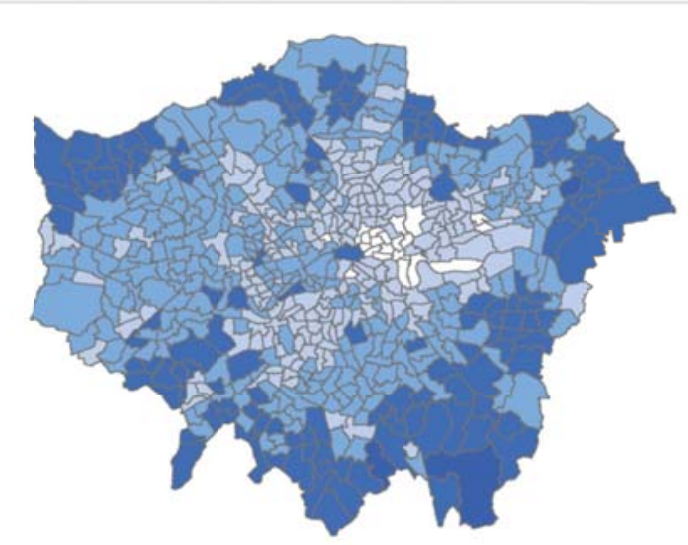

Age 45 to 64

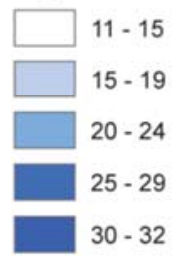

Figure 7. Maps showing the two age variables: a) percentage of population aged 30-44 and b) percentage of population aged 45 to 64 . Maps are shown with the same colour schemes, to emphasise the complementarity of the two geographical distributions. 
Accepted to Electoral Studies (7 Oct 2015)

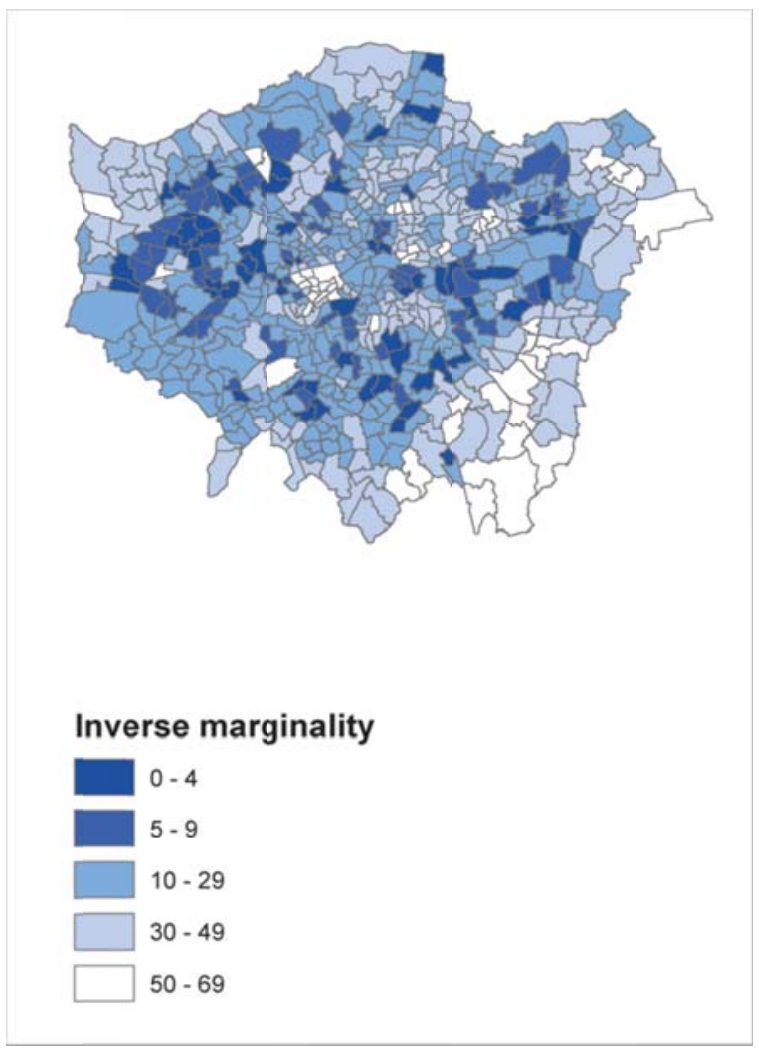

Figure 8. Spatial distribution of the inverse marginality. 
Tables

Table 1. The fourteen independent variables originally considered for inclusion in regression modelling. The three variables found to be correlated with the highest number of other variables (PCT18TO29, PCT65PLUS and OWNOCC, shown on shaded fields in the table) were excluded from GWR modelling. Further, the variables marked with ** (STUDENTS, POPDIFF, NOCENTHEAT) were excluded during the model quality optimisation, leaving a set of eight variables (shown in bold) to be included in the final model

\begin{tabular}{|c|c|c|c|c|}
\hline \multicolumn{2}{|r|}{ Group } & Variable & Name & Highly correlated* with: \\
\hline 1 & $\begin{array}{c}\text { Age } \\
\text { variables }\end{array}$ & $\begin{array}{l}\text { Percentage of population } \\
\text { aged } 18-29\end{array}$ & PCT18TO29 & $\begin{array}{l}\text { PCT45TO64, PCT65PLUS, } \\
\text { STUDENTS, RECMIG, } \\
\text { OWNOCC }\end{array}$ \\
\hline 2 & & $\begin{array}{l}\text { Percentage of population } \\
\text { aged } 30-44\end{array}$ & РCT30TO44 & \\
\hline 3 & & $\begin{array}{l}\text { Percentage of population } \\
\text { aged } 45-64\end{array}$ & РCT45TO64 & $\begin{array}{l}\text { PCT18TO29, PCT65PLUS, } \\
\text { OWNOCC }\end{array}$ \\
\hline 4 & & $\begin{array}{l}\text { Percentage of population } \\
\text { aged } 65+\end{array}$ & PCT65PLUS & $\begin{array}{l}\text { PCT18TO29, PCT45TO64, } \\
\text { OVERCROWD, OWNOCC }\end{array}$ \\
\hline 5 & Occupation & $\begin{array}{l}\text { Percentage of students aged } \\
16+\end{array}$ & STUDENTS** & PCT18TO29 \\
\hline 6 & & $\begin{array}{l}\text { Percentage of residents in } \\
\text { professional or managerial } \\
\text { occupations }\end{array}$ & PROFMGR & \\
\hline 7 & Migration & $\begin{array}{l}\text { Percentage of change in } \\
\text { population 2011-2011 }\end{array}$ & POPDIFF** $^{* *}$ & \\
\hline 8 & & $\begin{array}{l}\text { Percentage of recent } \\
\text { immigrants (living in London } \\
\text { for less than } 2 \text { years) }\end{array}$ & RECMIG & РCT18TO29 \\
\hline 9 & Population & Population density & POPDENSITY & \\
\hline 10 & $\begin{array}{c}\text { Economic } \\
\text { deprivation } \\
\text { - labour } \\
\text { market }\end{array}$ & Percentage of unemployment & UNEMPLOY & OVERCROWD \\
\hline 11 & $\begin{array}{l}\text { Economic } \\
\text { deprivation }\end{array}$ & $\begin{array}{l}\text { Percentage of overcrowded } \\
\text { households }\end{array}$ & OVERCROWD & PCT65PLUS, UNEMPLOY \\
\hline 12 & $\begin{array}{l}\text { - housing } \\
\text { market }\end{array}$ & $\begin{array}{l}\text { Percentage of households } \\
\text { with no central heating }\end{array}$ & NOCENHEAT** & \\
\hline 13 & & $\begin{array}{l}\text { Percentage of owner- } \\
\text { occupied households }\end{array}$ & OWNOCC & $\begin{array}{l}\text { PCT18TO29, PCT45TO64, } \\
\text { PCT65PLUS }\end{array}$ \\
\hline 14 & $\begin{array}{c}\text { Political } \\
\text { context }\end{array}$ & $\begin{array}{l}\text { Inverse marginality in } 2008 \\
\text { London Mayoral election }\end{array}$ & MARGINALIT & \\
\hline
\end{tabular}


Table 2. Results of the global regression and summary statistics for GWR parameter estimates. All variables are statistically significant to 0.01 level in global regression (marked with ${ }^{*}$ ), except for percentage of younger adults (aged 30 to 44 ).

\begin{tabular}{|c|c|c|c|c|c|c|}
\hline \multirow[t]{2}{*}{ Variable } & \multicolumn{2}{|c|}{ Global regression: } & \multicolumn{4}{|c|}{ GWR parameter estimates $\beta(i)$ : } \\
\hline & $\beta$ & & Min & Iax & & StDev \\
\hline РCT30TO44 & -0.107 & -1.903 & -0.770 & 0.737 & -0.095 & 0.294 \\
\hline РCT45TO64 & 0.461 & $6.699 *$ & -0.616 & 1.836 & 0.586 & 0.500 \\
\hline PROFMGR & 0.484 & $19.835 *$ & 0.075 & 1.294 & 0.411 & 0.186 \\
\hline RECMIG & -1.138 & $-16.762 *$ & -2.047 & 1.314 & -0.745 & 0.562 \\
\hline UNEMPLOY & -1.327 & $-8.590 *$ & -4.469 & 1.856 & -1.073 & 0.924 \\
\hline OVERCROWD & 0.7742 & $15.789 *$ & -0.380 & 1.510 & 0.519 & 0.353 \\
\hline MARGINALIT & 0.019 & $2.174 *$ & -0.138 & 0.164 & 0.026 & 0.063 \\
\hline POPDENSITY & 0.014 & $3.7271 *$ & -0.032 & 0.113 & 0.019 & 0.028 \\
\hline
\end{tabular}


Table 3. Spatial autocorrelation of standardised residuals for the global and local model. Moran's I values are higher and positive for global residuals than for GWR residuals, indicating a higher level of spatial autocorrelation. Moran's I for GWR is close to zero, indicating a close to random spatial pattern. All index values are significant to 0.01 level (as per p-values).

\begin{tabular}{c|ccr}
\hline \multicolumn{1}{c|}{ Spatial autocorrelation model } & \multicolumn{3}{|c}{ Spatial autocorrelation results } \\
\hline Model 1: & Global Residuals & \\
- Spatial relationship: & Moran's I & z-score & p-value \\
inverse Euclidean & 0.379912 & 17.484839 & 0.000000 \\
distance squared & Local (GWR) Residuals & & \\
- Row standardisation & Moran's I & z-score & p-value \\
& 0.070824 & 3.319104 & 0.000903 \\
& Global Residuals & & \\
\hline Model 2: & Moran's I & z-score & p-value \\
Spatial relationship: & 0.390008 & 16.561819 & 0.000000 \\
contiguity of polygons & Local GWR Residuals & & \\
(edges and corners) & Moran's I & z-score & p-value \\
Row standardisation & 0.061216 & 2.656541 & 0.007895 \\
\hline
\end{tabular}

